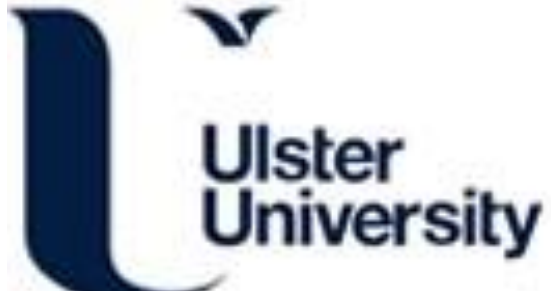

\section{Constructing a filler network for thermal conductivity enhancement in epoxy composites via reaction-induced phase separation}

Zhang, Y., Shen, YC., Shi, K., Wang, TW., \& Harkin-Jones, E. (2018). Constructing a filler network for thermal conductivity enhancement in epoxy composites via reaction-induced phase separation. Composites Part $A$ : Applied Science and Manufacturing, 110, 62-69. https://doi.org/10.1016/j.compositesa.2018.04.009

Link to publication record in Ulster University Research Portal

\section{Published in:}

Composites Part A: Applied Science and Manufacturing

Publication Status:

Published (in print/issue): 01/07/2018

DOI:

10.1016/j.compositesa.2018.04.009

\section{Document Version}

Author Accepted version

\section{General rights}

Copyright for the publications made accessible via Ulster University's Research Portal is retained by the author(s) and / or other copyright owners and it is a condition of accessing these publications that users recognise and abide by the legal requirements associated with these rights.

\section{Take down policy}

The Research Portal is Ulster University's institutional repository that provides access to Ulster's research outputs. Every effort has been made to ensure that content in the Research Portal does not infringe any person's rights, or applicable UK laws. If you discover content in the Research Portal that you believe breaches copyright or violates any law, please contact pure-support@ulster.ac.uk. 


\title{
Constructing a filler network for thermal conductivity enhancement in epoxy composites via reaction-induced phase separation
}

\author{
Yuwei Zhang ${ }^{\text {a }}$, Yucai Shen ${ }^{* a}$, Kunxiang Shi ${ }^{a}$, Tingwei Wang ${ }^{* a}$, Eileen \\ Harkin-Jones ${ }^{\mathrm{b}}$ \\ ${ }^{a}$ College of Materials Science and Engineering, Nanjing Tech University, Nanjing, \\ 210009, China \\ ${ }^{\mathbf{b}}$ School of Engineering, University of Ulster, Jordanstown BT37 0QB, UK
}

\begin{abstract}
Diglycidyl ethers of bisphenol-A (DGEBA)/methyl tetrahydrophthalic anhydride/polyethersulphone (PES) blends are prepared as matrix resins for thermally conductive composites using graphite nanoplatelets (GNPs) as the conductive component. The epoxy/PES blends form a network structure via reaction-induced phase separation (RIPS) during the curing process, and the GNPs are selectively localized in the PES phase and at the interface leading to a three-dimensional continuous filler network. With this unique structure, the thermal conductivity of the epoxy/PES/10 wt\% GNPs composite is increased to $0.709 \mathrm{~W} \mathrm{~m}^{-1} \mathrm{~K}^{-1}$, which is nearly 3.5 times that of the pure epoxy or a $52 \%$ increase compared to the epoxy/GNP composite without PES. In addition, it is found that the impact strength of the composite relative to the unfilled
\end{abstract}


material is also improved.

Keyword: A. Polymer-matrix composites (PMCs); B. Thermal properties; E. Cure

E-mail address: ycshen@njtech.edu.cn (Yucai Shen); wangtw@njtech.edu.cn (Tingwei Wang)

(The author Yucai Shen contributed equally to this work and should be considered co-first authors.)

\section{Introduction}

As the growth in development and use of electronic and electrical equipment continues unabated so also does the requirement for materials that can deal with the heat generated by such equipment. Without highly efficient thermal management, this heat generation can significantly lower lifetime and reliability of electrical components $[1,2]$. Since the majority of new electronic/electrical products are today made from a polymer based material which is intrinsically thermally insulating, there is an urgent need to develop new polymeric materials that are thermally conductive [3-5].

A variety of fillers such as carbon nanotubes [6,7], boron nitride [8-11], graphene nanoplatelets [12, 13], silicon carbide [14-16] and hybrid fillers [17-19] have been used to enhance the thermal conductivity of polymers because of their high thermal conductivity and large aspect ratio [20-23]. Various factors affect the thermal conductivity enhancement in the filled composites, such as the interfacial thermal 
resistance [24-27], the size [28, 29] and type [18, 30, 31] of fillers and the distribution of fillers $[12,32,33]$.

To achieve a high thermal conductivity in a composite it is essential to achieve a network of the conductive particles in the polymer matrix [34, 35]. Building such networks in a polymer composite has been the subject of significant research effort in recent years. One method is to design a segregated structure [8, 10, 12, 33-38] including three steps: (1) fabrication of micron-sized polymer particles; (2) coating of conductive fillers onto the surface of the polymer particles; and (3) compression molding of the filler coated polymer particles. This is a relatively straightforward method but the compression moulding process itself is not commercially significant and therefore of limited interest. Another approach is to construct a freestanding filler framework as the heat transfer network, such as a graphene aerogel [39-41], BNNS aerogel [42, 43] or complex aerogel $[9,44-46]$, and then encasing the network in a thermosetting matrix such as epoxy. Jiang et al. [9] prepared a cellulose nanofiber supported boron nitride aerogel via sol-gel and freeze-drying, followed by casting with epoxy. The composites exhibit thermal conductivity enhancement of about $1400 \%$ at a low BNNS loading of 9.6 vol\%. However, this method normally needs multiple processing steps, and it is time-consuming and difficult for large-scale fabrication.

Another approach is the selective distribution of fillers in an immiscible polymer blend with a co-continuous structure [33, 47-51], a strategy that has also been applied in 
the design of electrically conductive composites [52-55]. For example, it has been found that silicon carbide will aggregate in a single polymer phase in an immiscible PS/PVDF blend to form an efficient thermally conductive network [33]. Due to the simplicity of melt blending, this method has good commercial potential (to the best of our knowledge this approach is used mainly with thermoplastic/thermoplastic systems and is rarely reported for thermosetting systems). While the selective distribution of fillers at the interface can result in a continuous network of fillers at a low filler loading [32], this is not easy to achieve experimentally. One method however that offers some potential is that of reaction-induced phase separation (RIPS) of thermosetting/thermoplastic resin composite systems [56-59]. These blends can form sea-island structures, co-continuous phase structures or phase inversion structures depending on the content of thermoplastic thus offering a potential strategy for better control of the network formation in a composite. This approach is adopted in the current work whereby a polyethersulphone (PES) modified-epoxy system is selected as the matrix and graphite nanoplatelets (GNPs) selected as the thermally conductive filler to produce thermally conductive composites. The effect of GNP content on the thermal conductivity and mechanical properties of the composites is investigated. Compared to the co-continuous structures obtained in previous work, the network-density of the phase inversion structure in this paper is improved. In addition, the straightforward preparation method and ability to easily tune the thermal conductivity of the composites has good potential for scale up to 
more commercial applications.

\section{Experimental}

\subsection{Materials}

Graphite nanoplatelets (GNPs) (diameter: 5 40 $\mu \mathrm{m}$, thickness: $<100 \mathrm{~nm}$, density: 0.25 0.3 g/ $\mathrm{cm}^{3}$ ) were supplied by Changzhou MoZhiCui technology Co. Ltd., China. The epoxy resin was a low molar mass liquid diglycidyl ether of bisphenol A (E51) provided by Nantong Xingchen Synthetic Material Co. Ltd, China. Polyethersulfone (PES, number-average molecular weight: $\mathrm{Mn}=6.7 \times 10^{4}$ and an intrinsic viscosity of $0.36 \mathrm{dL} / \mathrm{g}$ ) was supplied by Jilin University, China. The curing agent was methyl tetrahydrophthalic anhydride (MTHPA), purchased from Zhejiang Alpha Chemical Technology Co. Ltd. 2-ethyl-4-methylimidazole (Sinopharm Group Chemical Reagent Co. Ltd., China) was used as an accelerator.

\subsection{Composite Preparation}

The epoxy/PES/GNPs composites were made using the following procedure. Firstly, the PES powder was mixed with the liquid curing agent MTHPA at room temperature. The mixture was heated in an oil bath at $110{ }^{\circ} \mathrm{C}$ for $2 \mathrm{~h}$ to dissolve the PES in the liquid MTHPA. After the mixture was cooled to $90{ }^{\circ} \mathrm{C}$, the required amount of epoxy (epoxy: MTHPA $=5: 4$, by weight ratio) was added to the mixture under continuous stirring for $30 \mathrm{~min}$. Then, different contents of GNPs ( $1 \mathrm{wt} \%, 3 \mathrm{wt} \%, 5 \mathrm{wt} \%, 7 \mathrm{wt} \%, 10 \mathrm{wt} \%$ and 
$15 \mathrm{wt} \%$ of epoxy/PES blend) were added with mechanical stirring for $30 \mathrm{~min}$, and the mixture was degassed. The compositions were cured at $145{ }^{\circ} \mathrm{C}$ for 4 h. Fig. 1 shows the processing steps used to fabricate the composites. Epoxy/2-ethyl-4-methylimidazole/GNPs composites without PES were also prepared as a reference material.

\subsection{Characterization}

\subsubsection{Contact angle measurements}

The surface tension of all the components was measured using contact angle measurements. Before the measurement, films of PES and GNPs were prepared by hot-pressing [60] and the uncured epoxy was coated on a glass slide [61]. Contact angle was measured at $25{ }^{\circ} \mathrm{C}$ with a drop shape analysis system (DSA100, KRUSS). Measurement of a given contact angle was carried out at least 5 times. Double distilled water $\left(\mathrm{H}_{2} \mathrm{O}\right)$ and methylene iodide $\left(\mathrm{CH}_{2} \mathrm{I}_{2}\right)$ were used as probe liquids. The dispersive and polar components of the surface tension are 22.5 and $50.5 \mathrm{dyn}^{-1}$ for water and 48.5 and $2.3 \mathrm{dyn} \mathrm{cm}^{-1}$ for methylene iodide, respectively [62].

\subsubsection{Thermal conductivity measurements}

The thermal conductivity was measured using a Hot Disk thermal analyzer (TPS-2500), and based upon the transient plane source (TPS) method [63]. The dimension of the samples was $30 \times 30 \times 8 \mathrm{~mm}$ with the sensor placed between two similar slabs of materials. The senor supplied a heat pulse of $0.08 \mathrm{~W}$ for $5 \mathrm{~s}$ to the sample and 
the subsequent change in temperature was recorded. The thermal conductivity of the samples was obtained by fitting the data according to Gustavsson et al. [64]. The temperature of the composites was recorded using an infrared thermograph (FOTRIC 220).

2.3.3 Scanning electron microscopy (SEM), optical microscopy (OM) and transmission electron microscopy (TEM)

The microstructure of the cured epoxy blends and dispersibility of the GNPs filler were observed using a JSM-6510 scanning electron microscope (SEM, Jeol, Japan) and a metallographic microscope (Axio Observer A1m, Carl Zeiss Jena, Germany). The internal microstructure of the composites was characterized using transmission electron microscopy (TEM). The TEM measurements were performed using a Technai 12 transmission electron microscope (FEI) at an acceleration voltage of $120 \mathrm{kV}$. To prepare the SEM samples, the specimens were first fractured in liquid nitrogen and then sputter-coated with a thin layer of gold. SEM measurements were performed on a SEM (JSM-6510). To prepare the TEM samples (70 nm thickness), the composites were ultra-microtomed at room temperature using an ultramicrotome (Leica EM UC6). In order to observe the epoxy/PES blend structure, the material was sandwiched between two glass slides and cured at $145{ }^{\circ} \mathrm{C}$ for $2 \mathrm{~h}$ and observed in transmission mode. For the epoxy/PES/GNP composite structure, the specimen was polished with emery paper and observed in reflection mode. 
2.3.4 Impact strength measurement

Un-notched Izod impact testing was carried out on an Izod impact test machine (UJ-4, Chengde Machine Factory, China) according to ASTM D4812-2004.

\section{Results and discussion}

\subsection{Prediction for selective distribution of GNPs}

For the distribution of fillers in immiscible polymer blends, many studies have demonstrated that the factors affecting distribution of fillers are complex [65-68] and it is difficult to give a completely accurate prediction of the distribution. However, the surface tension of each component in the blend is considered an important factor for prediction of distribution. Based on thermodynamics, the wetting coefficient $\left(\omega_{\mathrm{a}}\right)$ suggested by Sumita et al. [69] is widely and relatively successfully used to forecast distribution $[32,49,60]$. Wetting coefficient $\left(\omega_{\mathrm{a}}\right)$ can be calculated according to equation (1):

$$
\omega_{\mathrm{a}}=\frac{\gamma_{\mathrm{GNPs}-\mathrm{B}}-\gamma_{\mathrm{GNPs}-\mathrm{A}}}{\gamma_{\mathrm{A}-\mathrm{B}}}
$$

where $\gamma_{\mathrm{GNPs}-\mathrm{B}}$ is the interfacial tension between the GNPs and polymer $\mathrm{B}, \gamma_{\mathrm{GNPs}-\mathrm{A}}$ is the interfacial tension between GNPs and polymer A, and $\gamma_{\mathrm{A}-\mathrm{B}}$ is the interfacial tension between polymers A and B. If $\omega_{\mathrm{a}}<-1$, GNPs will be located in polymer B. If $-1<\omega_{\mathrm{a}}<1$, GNPs will be located at the interface of the blend. If $\omega_{a}>1$, GNPs will be preferentially 
located in polymer $\mathrm{A}$.

The interfacial tension between two components, $\gamma_{\mathrm{A}-\mathrm{B}}$, can be calculated using the harmonic mean equation and the geometric mean equation [70].

The harmonic mean equation:

$$
\gamma_{\mathrm{A}-\mathrm{B}}=\gamma_{\mathrm{A}}+\gamma_{\mathrm{B}}-4\left(\frac{\gamma_{\mathrm{A}}^{\mathrm{d}} \gamma_{\mathrm{B}}^{\mathrm{d}}}{\gamma_{\mathrm{A}}^{\mathrm{d}}+\gamma_{\mathrm{B}}^{\mathrm{d}}}+\frac{\gamma_{\mathrm{A}}^{\mathrm{p}} \gamma_{\mathrm{B}}^{\mathrm{p}}}{\gamma_{\mathrm{A}}^{\mathrm{p}}+\gamma_{\mathrm{B}}^{\mathrm{p}}}\right)
$$

and the geometric mean equation:

$$
\gamma_{\mathrm{A}-\mathrm{B}}=\gamma_{\mathrm{A}}+\gamma_{\mathrm{B}}-2\left(\sqrt{\gamma_{\mathrm{A}}^{\mathrm{d}} \gamma_{\mathrm{B}}^{\mathrm{d}}}+\sqrt{\gamma_{\mathrm{A}}^{\mathrm{p}} \gamma_{\mathrm{B}}^{\mathrm{p}}}\right)
$$

where $\gamma_{i}$ is the surface tension of component i. $\gamma_{i}^{d}$ is the dispersive portion of the surface tension of component $i$, and $\gamma_{i}^{p}$ is the polar portion of the surface tension of component i.

Surface tension, $\gamma_{i}$, is the sum of $\gamma_{i}^{\mathrm{d}}$ and $\gamma_{i}^{\mathrm{p}}$, and can be calculated from the contact angle $\Theta$. The relationship between $\Theta$ and $\gamma_{\mathrm{i}}$ is described using Owens-Wendt [71].

$$
\gamma_{L}(1+\operatorname{Cos} \theta)=2 \sqrt{\gamma_{s}^{\mathrm{d}} \gamma_{L}^{\mathrm{d}}}+2 \sqrt{\gamma_{\mathrm{s}}^{\mathrm{p}} \gamma_{\mathrm{L}}^{\mathrm{p}}}
$$

where $\gamma_{L}$ is the surface tension of the liquid and $\gamma_{L}^{d}$ and $\gamma_{L}^{d}$ are the dispersive and polar portions, respectively, of the liquid's surface tension.

The contact angles of $\mathrm{H}_{2} \mathrm{O}$ on the surfaces of PES, epoxy and GNPs were $73.0^{\circ}$, $58.5^{\circ}$, and $71.7^{\circ}$, respectively. The $\mathrm{CH}_{2} \mathrm{I}_{2}$ contact angles on the surfaces of PES, epoxy and GNPs were $50.5^{\circ}, 22.7^{\circ}$ and $28.8^{\circ}$, respectively. The surface energies were calculated using Equation (4) and are shown in Table 1). The interfacial tensions 
between each of the components were calculated according to Equation (2) and (3), and are shown in Table 2. Finally, wetting coefficient data for the epoxy/PES blends filled with GNPs were calculated according to Equation (1), and are shown in Table 3.

The value of wetting coefficient data lies between $-1 \sim 1$, hence it is predicted that the GNPs will tend to be selectively located at the interface of the PES phase and the epoxy phase.

\subsection{Microstructure of the epoxy/PES blends}

The morphologies of cured composites at various epoxy/PES weight ratios $($ epoxy $/ \mathrm{PES}=10 \mathrm{w} / 1 \mathrm{w}, 10 \mathrm{w} / 2 \mathrm{w}, 10 \mathrm{w} / 3 \mathrm{w})$ were characterized using OM (Fig. 2). At 10 wt\% of epoxy, the PES formed a large number of small domains (Fig. 2a); at $20 \mathrm{wt} \%$, a co-continuous phase structure was observed (Fig. 2b); and at $30 \mathrm{wt} \%$, phase inversion occurred (i.e., epoxy forms small phase domains throughout the PES matrix) (Fig. 2c).

Fig. 3 shows the phase inversion structure of the fractured surface of epoxy/PES $($ epoxy/PES $=10 \mathrm{w} / 3 \mathrm{w})$. The phase components were analyzed using SEM and energy dispersive spectrometry [72]. The results reveal that the network phase (area 2) contains a greater amount of sulfur compared to the isolated spherical domain phase (area 1), meaning that the network phase is the PES phase, and the isolated spherical domain phase is the epoxy phase. Among the epoxy/PES compositions, epoxy/PES (epoxy/PES $=10 \mathrm{w} / 3 \mathrm{w}$ ) was chosen as a suitable matrix composition, because a phase inversion structure was expected to be a favorable template for distributing GNPs to form an 
effective network.

\subsection{Microstructures of epoxy/PES/GNP composites}

Fig. 4 shows the cross-section of the epoxy/PES/GNP and epoxy/GNP composites with various filler content. In the epoxy/PES/GNPs composites (Fig. 4A D), it can be seen that PES formed a continuous phase in the blends and GNPs were observed in it. In other words, the GNPs were selectively distributed at the interface of the blends or in the PES phase. Additionally, the cross-section images demonstrate that GNPs gradually contact with each other to form a filler pathway with increasing GNP content. When GNP content increased to $10 \mathrm{wt} \%$, the GNPs tended to connect together to construct a filler network. However, a further increase in GNP content (15 wt $\%)$ led to significant changes in the morphology of the composite, and only a few epoxy domains are clearly observed in Fig. 4D. This occurs because when the GNP content reaches $15 \mathrm{wt} \%$, the difference in matrix viscosity increases rapidly and the compatibility of the matrix changes, which in turn leads to an incomplete phase inversion structure, as shown in Fig. 4D and Fig. 5D. This means that a 3D interconnected template is not formed and thus a 3D interconnected filler network is not formed [52, 73]. For comparison, the distribution of GNPs in the epoxy composites without PES is random, as shown in Fig. $4 \mathrm{a} \sim \mathrm{d}$.

Due to the reflective characteristic of GNPs, the distribution of GNPs can also be 
clearly observed by OM as shown in Fig. 5. In Fig. 5A and 5B, the arrows indicate the locations of GNPs (GNPs are observed as white spots under xenon lamp irradiation), the filler network structure has not yet been built. When the filler content reaches 10 wt\%, the filler network is formed. These results are consistent with the SEM observations.

Both SEM and OM images provide a powerful and direct proof of GNP network formation throughout the entire matrix, but TEM is required to observe the detailed location of GNPs.

The selective distribution of GNPs in the composites was visualized using TEM (Fig. 6). The dark gray domain is the PES phase, whereas the light gray domain is the epoxy phase. GNPs (shown by arrows) are located at the interface, and also in the PES phase near the interface which may have resulted from a smaller interfacial tension between the PES and GNPs. This observation is generally consistent with the prediction based on wetting coefficient.

\subsection{Thermal conductivity of epoxy/PES/GNPs composites}

Fig. 7 shows the thermal conductivities of epoxy/GNPs and epoxy/PES/GNPs $($ epoxy/PES $=10 \mathrm{w} / 3 \mathrm{w})$ composites with different GNPs content.

The thermal conductivity of epoxy/PES/GNPs composites and epoxy/GNPs composites are relatively close when the GNPs content is small (1 7 wt $\%)$. However, significant enhancement was observed in the thermal conductivity of epoxy/PES/GNPs 
composites as GNPs content increased to $10 \mathrm{wt} \%$ comparing with epoxy/GNPs composites at the same filler loading. This demonstrates that $10 \mathrm{wt} \%$ GNPs content may be a critical level for these epoxy composites. At small GNPs content, there are insufficient GNPs to form a percolated, thermally conductive pathway. With further increases in GNPs content, thermal conductivity in epoxy/PES/GNPs composites increases remarkably. This is attributed to the formation of a three-dimensional filler network via RIPS. Therefore, improved thermal conductivity of epoxy composites can be achieved efficiently by the formation of filler network via RIPS, i.e. the thermal transfer efficiency per unit mass of filler is increased by this strategy.

In order to demonstrate the thermal performance of epoxy/PES/10 wt $\%$ GNPs composites, the surface temperature variations of the composites with time during heating were recorded using an infrared thermograph. All the samples were placed on a hot stage at $80{ }^{\circ} \mathrm{C}$. The epoxy/PES/10 wt $\%$ GNPs composite has a much better thermal response due to its higher thermal conductivity, and the surface temperature of epoxy/PES/10 wt\% GNPs composite continuously increases with time, at a higher rate, as shown in Fig. 8. These results illustrate that epoxy/PES/10 wt $\%$ GNPs composite has enhanced thermal conductivity.

\subsection{Impact strength of epoxy/PES/GNPs composites}

The impact strength of epoxy/PES/GNPs composites is shown in Table 4. It can be seen that the impact strength of pure epoxy and epoxy/PES without GNPs have little 
differences, but the impact strength of epoxy composites with $1 \sim 10$ wt $\%$ GNPs increases by $10 \sim 30 \%$ relative to pure epoxy. The GNPs which are located at the interface and in PES phase near the interface, may have enhanced the binding force of the interface and the toughness of the PES phase [74]. However, when the GNPs content reaches $15 \mathrm{wt} \%$, the impact strength decreases again. This may be due to aggregates of GNPs acting as stress concentrators [25].

\section{Conclusions}

Using RIPS, an epoxy/PES blend can form a phase inverted structure. This phase inverted structure functions as a template for GNPs to form a three-dimensional connected network structure. The self-assembled structure of GNPs within the PES phase leads to a composite with a high thermal conductivity at a relatively low GNPs loading. This concept is illustrated in Fig. 9. Impact strength tests indicate that mechanical properties of these composites are not compromised.

\section{Acknowledgments}

The authors are grateful for the support and funding from the Natural Science Foundation of Jiangsu Province (BK20150956), National Natural Science Foundation of China (No. 51703096), and the Priority Academic Program Development of Jiangsu Higher Education Institutions (PAPD). 


\section{Reference}

[1] Zhi C, Bando Y, Tang C, Kuwahara H, Golberg D. Large-scale fabrication of boron nitride nanosheets and their utilization in polymeric composites with improved thermal and mechanical properties. Adv Mater 2009; 21(28): 2889-93.

[2] Moore A L, Shi L. Emerging challenges and materials for thermal management of electronics. Mater Today 2014; 17(4): 163-74.

[3] Shan X, Liu Y, Wu Z, Liu H, Zhang Z, Huang R, et al. Preparation and property study of graphene oxide reinforced epoxy resin insulation nanocomposites with high heat conductivity. IOP Conference Ser Mater Sci Eng 2017; 171(1): 12151.

[4] Kholmanov I, Kim J, Ou E, Ruoff R S, Shi L. Continuous carbon nanotube-ultrathin graphite hybrid foams for increased thermal conductivity and suppressed subcooling in composite phase change materials. Acs Nano 2015; 9(12): 11699-707.

[5] Kuang Z, Chen Y, Lu Y, Liu L, Hu S, Wen S, et al. Fabrication of highly oriented hexagonal boron nitride nanosheet/elastomer nanocomposites with high thermal conductivity. Small 2015; 11(14): 1655-9.

[6] Ding P, Zhuang N, Cui X, Shi L, Song N, Tang S. Enhanced thermal conductive property of polyamide composites by low mass fraction of covalently grafted graphene nanoribbons. J Mater Chem C 2015; 3(42): 10990-7.

[7] Zhang W, Xu X, Yang J, Huang T, Zhang N, Wang Y, et al. High thermal conductivity of poly(vinylidene fluoride)/carbon nanotubes nanocomposites achieved by adding 
polyvinylpyrrolidone. Compos Sci Technol 2015; 106: 1-8.

[8] Jiang Y, Liu Y, Min P, Sui G. BN@PPS core-shell structure particles and their 3D segregated architecture composites with high thermal conductivities. Compos Sci Technol 2017; 144: 63-9.

[9] Chen J, Huang X, Zhu Y, Jiang P. Cellulose nanofiber supported 3d interconnected bn nanosheets for epoxy nanocomposites with ultrahigh thermal management capability. Adv Funct Mater 2017; 27(5): 1604754.

[10] Wang X, Wu P. Preparation of highly thermally conductive polymer composite at low filler content via a self-assembly process between polystyrene microspheres and boron nitride nanosheets. Acs Appl Mater Inter 2017; 9(23): 19934-44.

[11] Li Y, Xu G, Guo Y, Ma T, Zhong X, Zhang Q, et al. Fabrication, proposed model and simulation predictions on thermally conductive hybrid cyanate ester composites with boron nitride fillers. Compos Part A - Appl Sci 2018; 107: 570-8.

[12] Wu K, Lei C, Huang R, Yang W, Chai S, Geng C, et al. Design and preparation of a unique segregated double network with excellent thermal conductive property. Acs Appl Mater Inter 2017; 9(8): 7637-47.

[13] Bai Q, Wei X, Yang J, Zhang N, Huang T, Wang Y, et al. Dispersion and network formation of graphene platelets in polystyrene composites and the resultant conductive properties. Compos Part A - Appl Sci 2017; 96: 89-98.

[14] Gu J, Lv Z, Wu Y, Zhao R, Tian L, Zhang Q. Enhanced thermal conductivity of 
SiCp/PS composites by electrospinning-hot press technique. Compos Part A - Appl Sci 2015; 79: 8-13.

[15] Gu J, Guo Y, Lv Z, Geng W, Zhang Q. Highly thermally conductive POSS-g-SiCp/UHMWPE composites with excellent dielectric properties and thermal stabilities. Compos Part A - Appl Sci 2015; 78: 95-101.

[16] Gu J, Zhang Q, Zhang J, Wang W. Studies on the preparation of polystyrene thermal conductivity composites. Polym-Plast Technol 2010; 49(13): 1385-9.

[17] Jiang Y, Sun R, Zhang H, Min P, Yang D, Yu Z. Graphene-coated ZnO tetrapod whiskers for thermally and electrically conductive epoxy composites. Compos Part A Appl Sci 2017; 94: 104-12.

[18] Gu J, Guo Y, Yang X, Liang C, Geng W, Tang L, et al. Synergistic improvement of thermal conductivities of polyphenylene sulfide composites filled with boron nitride hybrid fillers. Compos Part A - Appl Sci 2017; 95: 267-73.

[19] Hsiao M, Ma CM, Chiang J, Ho K, Chou T, Xie X, et al. Thermally conductive and electrically insulating epoxy nanocomposites with thermally reduced graphene oxide-silica hybrid nanosheets. Nanoscale 2013; 5(13): 5863.

[20] Wang J, Qiao J, Wang J, Zhu Y, Jiang L. Bioinspired hierarchical alumina-graphene oxide-poly(vinyl alcohol) artificial nacre with optimized strength and toughness. Acs Appl Mater Inter 2015; 7(17): 9281-6.

[21] Chen H, Ginzburg VV, Yang J, Yang Y, Liu W, Huang Y, et al. Thermal conductivity 
of polymer-based composites: Fundamentals and applications. Prog Polym Sci 2016; 59: 41-85.

[22] Lee J, Jung H, Yu S, Man Cho S, Tiwari VK, Babu Velusamy D, et al. Boron nitride nanosheets (bnnss) chemically modified by "grafting-from" polymerization of poly(caprolactone) for thermally conductive polymer composites. Chem-Asian J 2016; 11(13): 1921-8.

[23] Huang X, Wang S, Zhu M, Yang K, Jiang P, Bando Y, et al. Thermally conductive, electrically insulating and melt-processable polystyrene/boron nitride nanocomposites prepared by in situ reversible addition fragmentation chain transfer polymerization. Nanotechnology 2015; 26(1): 15705.

[24] Yan W, Zhang Y, Sun H, Liu S, Chi Z, Chen X, et al. Polyimide nanocomposites with boron nitride-coated multi-walled carbon nanotubes for enhanced thermal conductivity and electrical insulation. J Mater Chem A 2014; 2(48): 20958-65.

[25] Yang X, Tang L, Guo Y, Liang C, Zhang Q, Kou K, et al. Improvement of thermal conductivities for PPS dielectric nanocomposites via incorporating $\mathrm{NH}_{2}$-POSS functionalized $n$ BN fillers. Compos Part A - Appl Sci 2017; 101: 237-42.

[26] Shen X, Wang Z, Wu Y, Liu X, Kim J. Effect of functionalization on thermal conductivities of graphene/epoxy composites. Carbon 2016; 108: 412-22.

[27] Ding P, Zhang J, Song N, Tang S, Liu Y, Shi L. Growing polystyrene chains from the surface of graphene layers via RAFT polymerization and the influence on their thermal 
properties. Compos Part A - Appl Sci 2015; 69: 186-94.

[28] Wang F, Drzal LT, Qin Y, Huang Z. Mechanical properties and thermal conductivity of graphene nanoplatelet/epoxy composites. J Mater Sci 2015; 50(3): 1082-93.

[29] Shen X, Wang Z, Wu Y, Liu X, He Y, Kim J. Multilayer graphene enables higher efficiency in improving thermal conductivities of graphene/epoxy composites. Nano Lett 2016; 16(6): 3585-93.

[30] Hu Y, Shen J, Li N, Ma H, Shi M, Yan B, et al. Comparison of the thermal properties between composites reinforced by raw and amino-functionalized carbon materials. Compos Sci Technol 2010; 70(15): 2176-82.

[31] Yu A, Ramesh P, Sun X, Bekyarova E, Itkis ME, Haddon RC. Enhanced thermal conductivity in a hybrid graphite nanoplatelet - carbon nanotube filler for epoxy composites. Adv Mater 2008; 20(24): 4740-4.

[32] Huang J, Zhu Y, Xu L, Chen J, Jiang W, Nie X. Massive enhancement in the thermal conductivity of polymer composites by trapping graphene at the interface of a polymer blend. Compos Sci Technol 2016; 129: 160-5.

[33] Cao J, Zhao J, Zhao X, You F, Yu H, Hu G, et al. High thermal conductivity and high electrical resistivity of poly(vinylidene fluoride)/polystyrene blends by controlling the localization of hybrid fillers. Compos Sci Technol 2013; 89: 142-8.

[34] Gong J, Liu Z, Yu J, Dai D, Dai W, Du S, et al. Graphene woven fabric-reinforced polyimide films with enhanced and anisotropic thermal conductivity. Compos Part A - 
Appl Sci 2016; 87: 290-6.

[35] Cui X, Ding P, Zhuang N, Shi L, Song N, Tang S. Thermal conductive and mechanical properties of polymeric composites based on solution-exfoliated boron nitride and graphene nanosheets: a morphology-promoted synergistic effect. Acs Appl Mater Inter 2015; 7(34): 19068-75.

[36] Alam FE, Dai W, Yang M, Du S, Li X, Yu J, et al. In situ formation of a cellular graphene frame work in thermoplastic composites leading to superior thermal conductivity. J Mater Chem A 2017; 5(13): 6164-9.

[37] Cui C, Yan D, Pang H, Jia L, Bao Y, Jiang X, et al. Towards efficient electromagnetic interference shielding performance for polyethylene composites by structuring segregated carbon black/graphite networks. Chin J Polym Sci 2016; 34(12): 1490-9.

[38] Zhou H, Deng H, Zhang L, Fu Q. Significant enhancement of thermal conductivity in polymer composite via constructing macroscopic segregated filler networks. Acs Appl Mater Inter 2017; 9(34): 29071-81.

[39] Lian G, Tuan C, Li L, Jiao S, Wang Q, Moon K, et al. Vertically aligned and interconnected graphene networks for high thermal conductivity of epoxy composites with ultralow loading. Chem Mater 2016; 28(17): 6096-104.

[40] Li X, Shao L, Song N, Shi L, Ding P. Enhanced thermal-conductive and anti-dripping properties of polyamide composites by 3D graphene structures at low filler content. Compos Part A - Appl Sci 2016; 88: 305-14. 
[41] Yang J, Zhang E, Li X, Zhang Y, Qu J, Yu Z. Cellulose/graphene aerogel supported phase change composites with high thermal conductivity and good shape stability for thermal energy storage. Carbon 2016; 98: 50-7.

[42] Zeng X, Yao Y, Gong Z, Wang F, Sun R, Xu J, et al. Ice-templated assembly strategy to construct $3 \mathrm{~d}$ boron nitride nanosheet networks in polymer composites for thermal conductivity improvement. Small 2015; 11(46): 6205-13.

[43] Shen H, Cai C, Guo J, Qian Z, Zhao N, Xu J. Fabrication of oriented hBN scaffolds for thermal interface materials. Rsc Adv 2016; 6(20): 16489-94.

[44] Shao L, Shi L, Li X, Song N, Ding P. Synergistic effect of BN and graphene nanosheets in 3D framework on the enhancement of thermal conductive properties of polymeric composites. Compos Sci Technol 2016; 135: 83-91.

[45] Liu Z, Shen D, Yu J, Dai W, Li C, Du S, et al. Exceptionally high thermal and electrical conductivity of three-dimensional graphene-foam-based polymer composites. Rsc Adv 2016; 6(27): 22364-9.

[46] Chen L, Hou X, Song N, Shi L, Ding P. Cellulose/graphene bioplastic for thermal management: Enhanced isotropic thermally conductive property by three-dimensional interconnected graphene aerogel. Compos Part A - Appl Sci 2018; 107: 189-96.

[47] Yorifuji D, Ando S. Enhanced thermal conductivity over percolation threshold in polyimide blend films containing $\mathrm{ZnO}$ nano-pyramidal particles: advantage of vertical double percolation structure. J Mater Chem 2011; 21(12): 4402-7. 
[48] Cao J, Zhao X, Zhao J, Zha J, Hu G, Dang Z. Improved thermal conductivity and flame retardancy in polystyrene/poly(vinylidene fluoride) blends by controlling selective localization and surface modification of sic nanoparticles. Acs Appl Mater Inter 2013; 5(15): 6915-24.

[49] Ma CG, Xi DY, Liu M. Epoxy resin/polyetherimide/carbon black conductive polymer composites with a double percolation structure by reaction-induced phase separation. J Compos Mater 2013; 47(9): 1153-60.

[50] Chen J, Cui X, Zhu Y, Jiang W, Sui K. Design of superior conductive polymer composite with precisely controlling carbon nanotubes at the interface of a co-continuous polymer blend via a balance of $\pi-\pi$ interactions and dipole-dipole interactions. Carbon 2017; 114: 441-8.

[51] Mao C, Zhu Y, Jiang W. Design of electrical conductive composites: tuning the morphology to improve the electrical properties of graphene filled immiscible polymer blends. Acs Appl Mater Inter 2012; 4(10): 5281-6.

[52] Huang J, Mao C, Zhu Y, Jiang W, Yang X. Control of carbon nanotubes at the interface of a co-continuous immiscible polymer blend to fabricate conductive composites with ultralow percolation thresholds. Carbon 2014; 73: 267-74.

[53] Chen J, Du X, Zhang W, Yang J, Zhang N, Huang T, et al. Synergistic effect of carbon nanotubes and carbon black on electrical conductivity of PA6/ABS blend. Compos Sci Technol 2013; 81:1-8. 
[54] Chen J, Shi Y, Yang J, Zhang N, Huang T, Chen C, et al. A simple strategy to achieve very low percolation threshold via the selective distribution of carbon nanotubes at the interface of polymer blends. J Mater Chem 2012; 22(42): 22244-398.

[55] Deng H, Lin L, Ji M, Zhang S, Yang M, Fu Q. Progress on the morphological control of conductive network in conductive polymer composites and the use as electroactive multifunctional materials. Prog Polym Sci 2014; 39(4): 627-55.

[56] Zhang Y, Shi W, Chen F, Han C C. Dynamically asymmetric phase separation and morphological structure formation in the epoxy/polysulfone blends. Macromolecules 2011; 44(18): 7465-72.

[57] Zhang Y, Chen F, Liu W, Zhao S, Liu X, Dong X, et al. Rheological behavior of the epoxy/thermoplastic blends during the reaction induced phase separation. Polymer 2014; 55(19): 4983-9.

[58] Wang M, Yu Y, Li S. Polymerization-induced phase separation in polyethersulfone modified epoxy resin systems: effect of curing reaction mechanism. Sci China Ser B 2007; 50(4): 554-61.

[59] Yu Y, Wang M, Gan W, Tao Q, Li S. Polymerization-induced viscoelastic phase separation in polyethersulfone-modified epoxy systems. J Phys Chem B 2004; 108(20): 6208-15.

[60] Liu C, Ma F, Zhang Z, Yang J, Wang Y, Zhou Z. Selective localization of organic montmorillonite in poly(L-lactide)/poly(ethylene vinyl acetate) blends and the resultant 
properties. Compos Part B - Eng 2017; 123: 1-9.

[61] Abbasian A, Ghaffarian SR, Mohammadi N, Fallahi D. The contact angle of thin-uncured epoxy films: thickness effect. Coll Surf A 2004; 236(1-3): 133-40.

[62] Wu D, Lin D, Zhang J, Zhou W, Zhang M, Zhang Y, et al. Selective localization of nanofillers: effect on morphology and crystallization of pla/pcl blends. Macromol Chem Phys 2011; 212(6): 613-26.

[63] Zhu D, Li X, Wang N, Wang X, Gao J, Li H. Dispersion behavior and thermal conductivity characteristics of $\mathrm{Al}_{2} \mathrm{O}_{3}-\mathrm{H}_{2} \mathrm{O}$ nanofluids. Curr Appl Phys 2009; 9(1): 131-9. [64] Gustavsson M, Karawacki E, Gustafsson SE. Thermal conductivity, thermal diffusivity, and specific heat of thin samples from transient measurements with hot disk sensors. Rev Sci Instrum 1994; 65(12): 3856-9.

[65] Goldel A, Marmur A, Kasaliwal GR, Potschke P, Heinrich G. Shape-dependent localization of carbon nanotubes and carbon black in an immiscible polymer blend during melt mixing. Macromolecules 2011; 44(15): 6094-102.

[66] Li Y, Wang S, Zhang Y, Zhang Y. Carbon black-filled immiscible polypropylene/epoxy blends. J Appl Polym Sci 2006; 99(2): 461-71.

[67] Wu G, Asai S, Sumita M, Yui H. Entropy penalty-induced self-assembly in carbon black or carbon fiber filled polymer blends. Macromolecules 2002; 35(3): 945-51.

[68] Gubbels F, Jerome R, Vanlathem E, Deltour R, Blacher S, Brouers F. Kinetic and thermodynamic control of the selective localization of carbon black at the interface of 
immiscible polymer blends. Chem Mater 1998; 10(5): 1227-35.

[69] Sumita M, Sakata K, Asai S, Miyasaka K, Nakagawa H. Dispersion of fillers and the electrical-conductivity of polymer blends filled with carbon-black. Polym Bull 1991; 25(2): $265-71$.

[70] Wu S. Polymer interface and adhesion. New York: M. Dekker;1982.

[71] Owens DK, Wendt RC. Estimation of the surface free energy of polymers. J Appl Polym Sci 1969; 13(8): 1741-7.

[72] Kishi H, Tanaka S, Nakashima Y, Saruwatari T. Self-assembled three-dimensional structure of epoxy/polyethersulphone/silver adhesives with electrical conductivity. Polymer 2016; 82: 93-9.

[73] Liu Y, Zhong X, Zhan G, Yu Y, Jin J. Effect of mesoscopic fillers on the polymerization induced viscoelastic phase separation at near- and off-critical compositions. J Phys Chem B 2012; 116(12): 3671-82.

[74] Gu J, Zhang Q, Li H, Tang Y, Kong J, Dang J. Study on preparation of $\mathrm{SiO}_{2} /$ epoxy resin hybrid materials by means of sol-gel. Polym-Plast Technol 2007; 46(12): 1129-34. 


\section{Figures caption:}

Fig. 1 Schematic showing the preparation of epoxy/PES/GNPs composites.

Fig. 2 OM images of epoxy/PES composites with various weight ratios: (a) $10 \mathrm{w} / 1 \mathrm{w}$; (b) $10 \mathrm{w} / 2 \mathrm{w}$; (c) $10 \mathrm{w} / 3 \mathrm{w}$

Fig. 3 SEM micrographs of phase inversion structure. The elemental content of areas in the micrographs was analyzed by energy dispersive spectrometer.

Fig. 4 SEM images of epoxy/PES/GNPs and epoxy/GNPs composites at different GNP contents. Epoxy/PES/GNPs: (A) 3 wt $\%$ GNPs; (B) 7 wt $\%$ GNPs ; (C) $10 \mathrm{wt} \%$ GNPs; (D) 15 wt $\%$ GNPs; epoxy/GNPs: (a) $3 \mathrm{wt} \%$ GNPs; (b) $7 \mathrm{wt} \%$ GNPs ; (c) $10 \mathrm{wt} \%$ GNPs; (d) $15 \mathrm{wt} \%$ GNPs.

Fig. 5 OM images of epoxy/PES/GNPs and epoxy/GNPs composites at different GNPs contents. Epoxy/PES/GNPs: (A) 3 wt $\%$ GNPs; (B) 7 wt $\%$ GNPs ; (C) $10 \mathrm{wt} \%$ GNPs; (D) 15 wt $\%$ GNPs; epoxy/GNPs: (a) 3 wt $\%$ GNPs; (b) 7 wt $\%$ GNPs ; (c) 10 wt $\%$ GNPs; (d) 15 wt $\%$ GNPs.

Fig. 6 TEM images of the GNP distribution in (a) the epoxy/PES/1 wt\% GNPs composite and (b) the epoxy/PES/7 wt\% GNPs composite.

Fig. 7 Thermal conductivities of epoxy/PES/GNPs and epoxy/GNPs composites as a function of GNP content.

Fig. 8 (a) IR images of (1) pure epoxy, (2) epoxy/10 wt $\%$ GNPs and (3) epoxy/PES/10 wt $\%$ GNPs with heating time; (b) surface temperature variation of samples with heating time

Fig. 9 Structure evolution of thermally conductive epoxy/PES/GNPs composites with RIPS

Table 1 The surface energy data of components.

Table 2 Interfacial tensions $\gamma_{\mathrm{A}-\mathrm{B}}$ between different components calculated using the harmonic and geometric mean equations. 
Table 3 Wetting coefficient as calculated using the harmonic and geometric mean equation.

Table 4 The impact strength of pure epoxy and epoxy composites

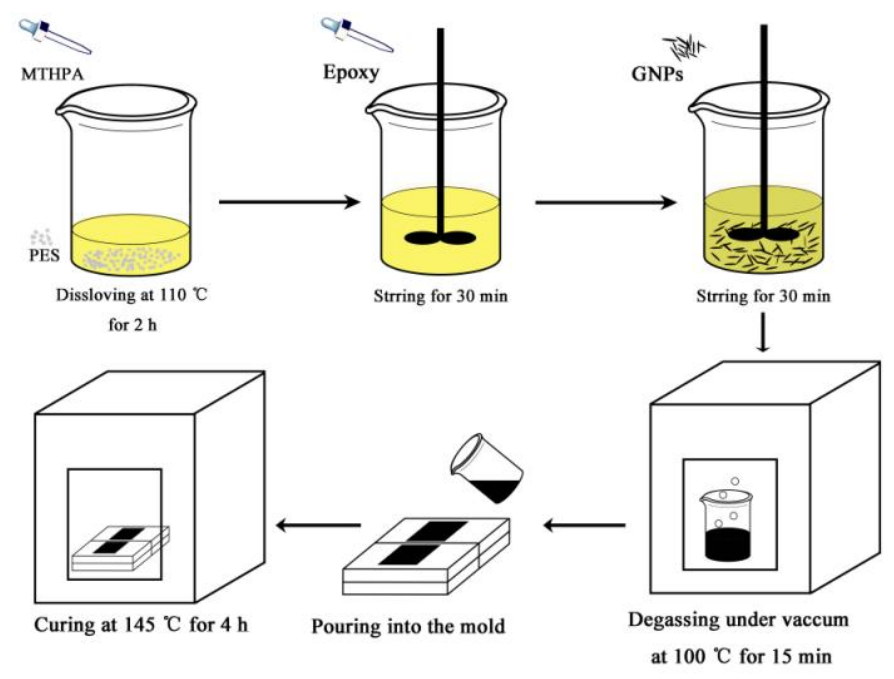

Fig. 1
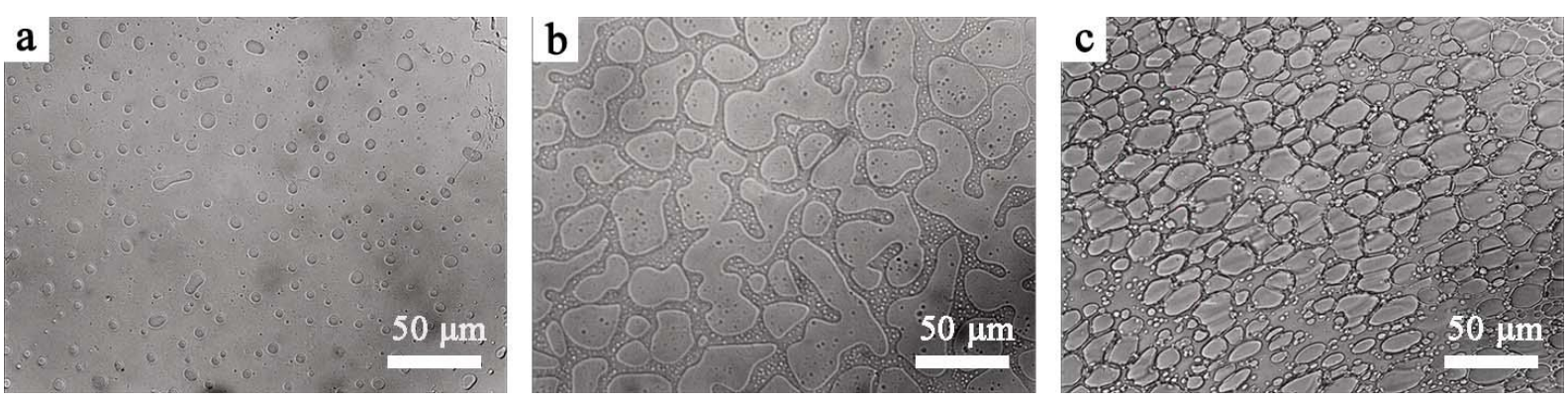

Fig. 2
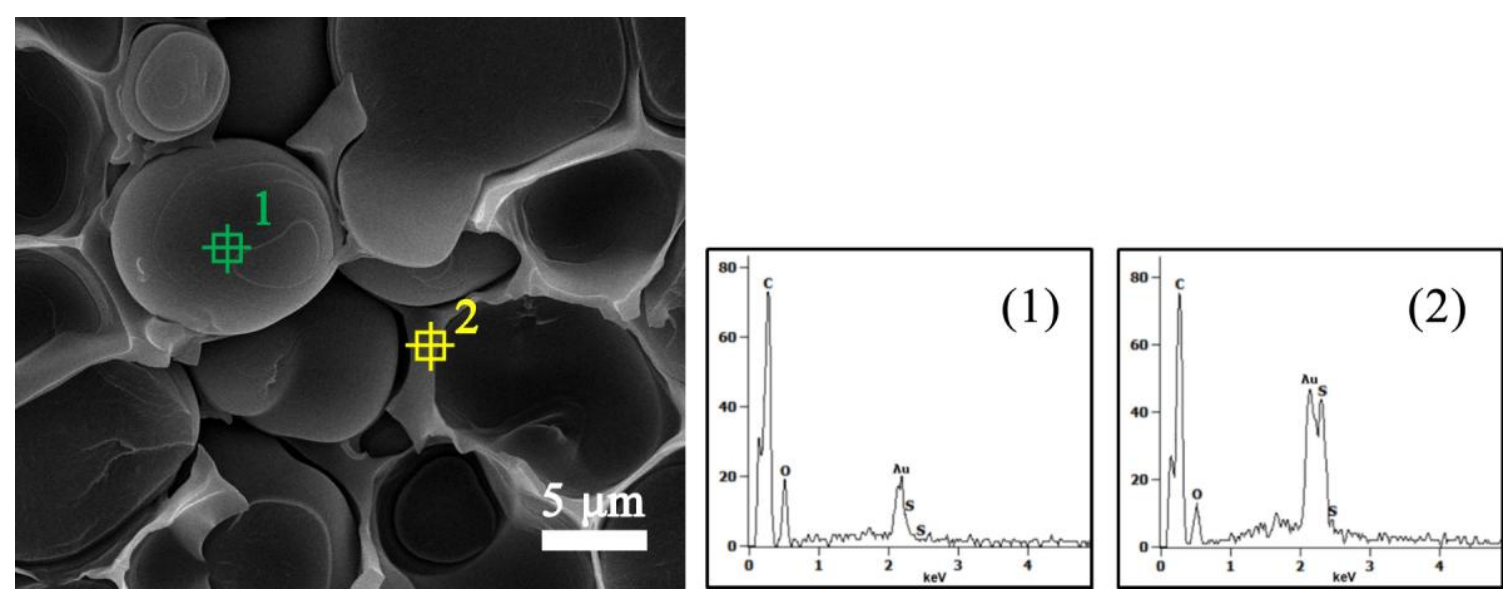
Fig. 3
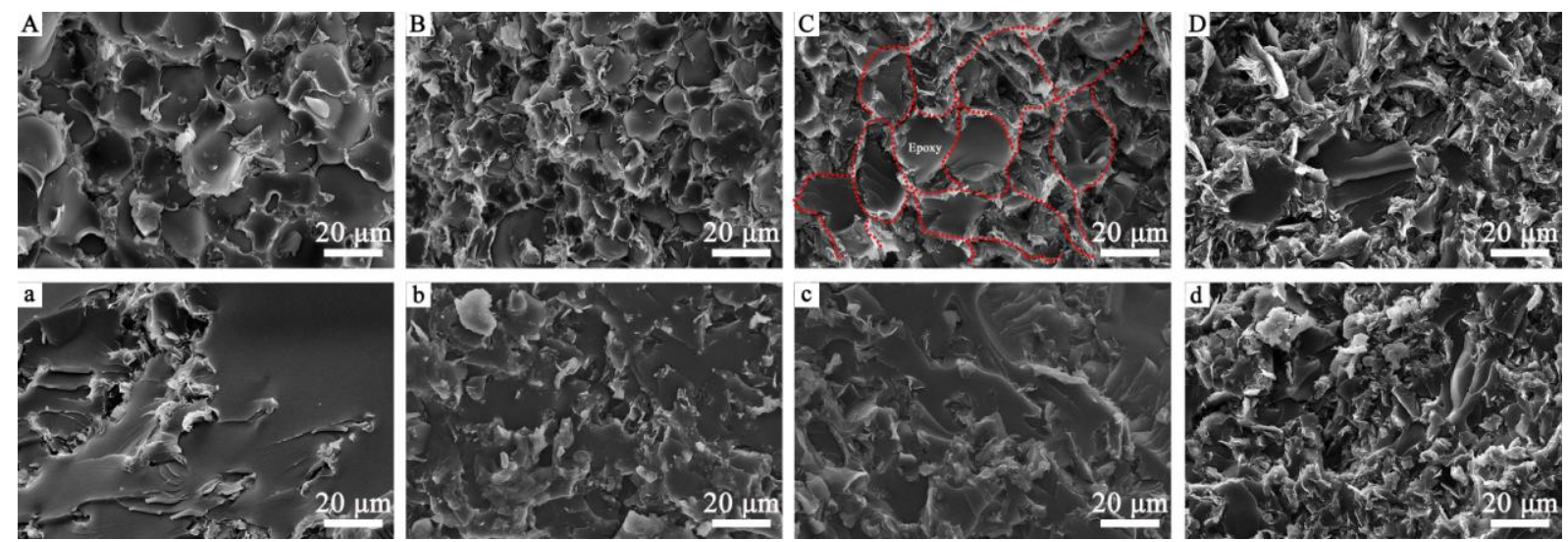

Fig. 4
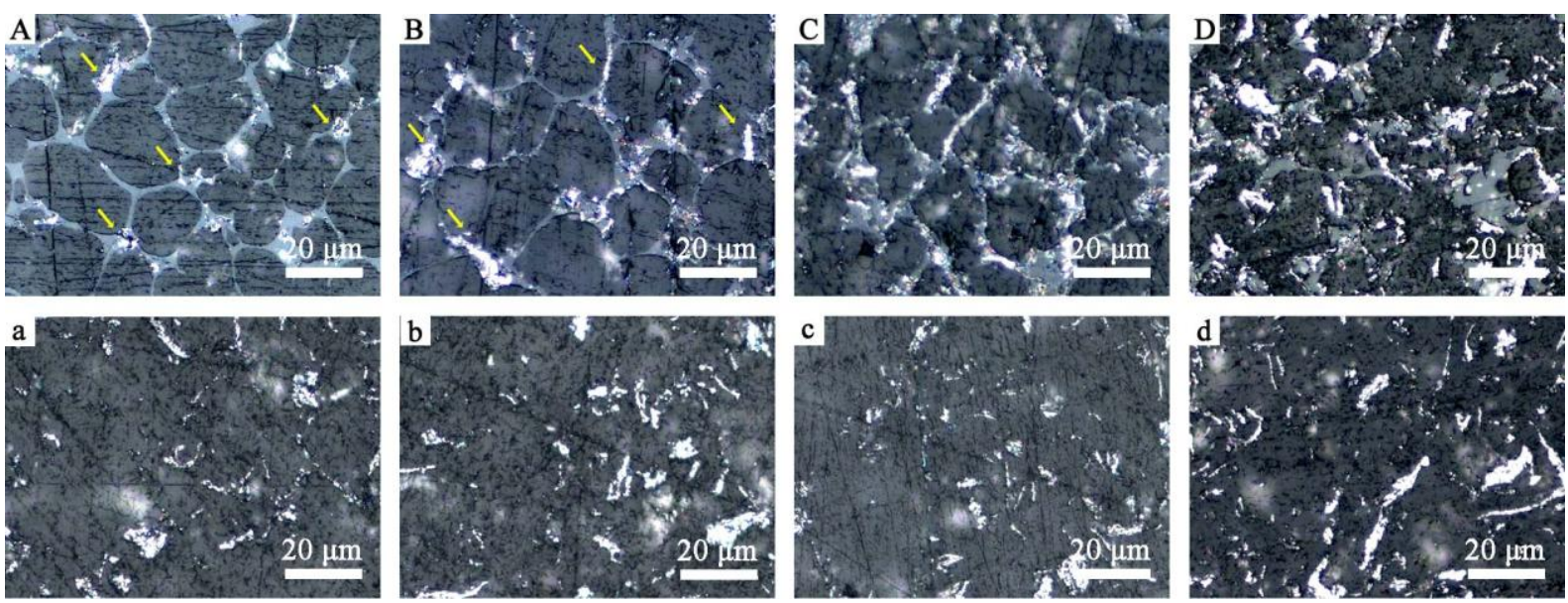

Fig. 5
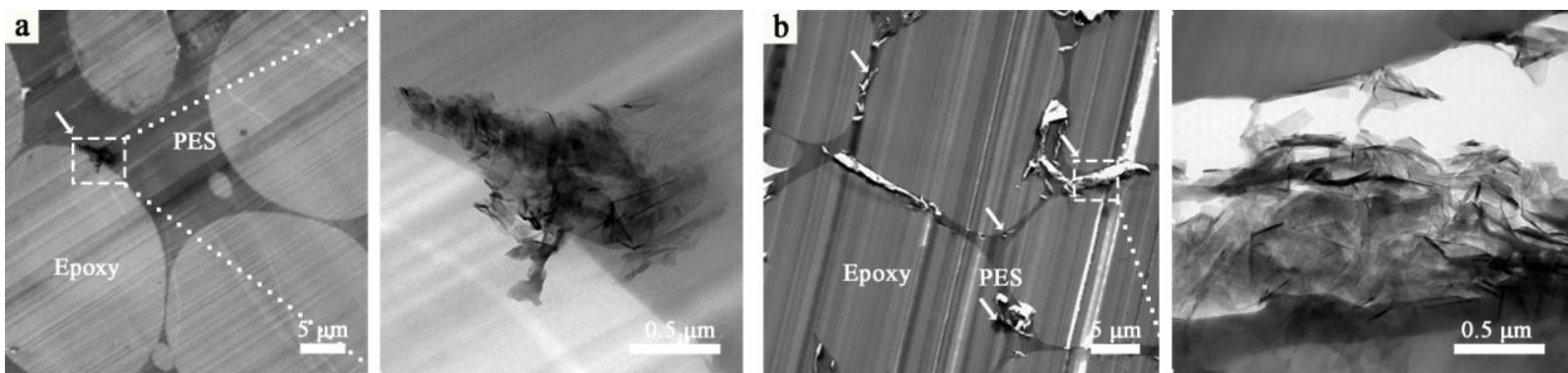

Fig. 6 


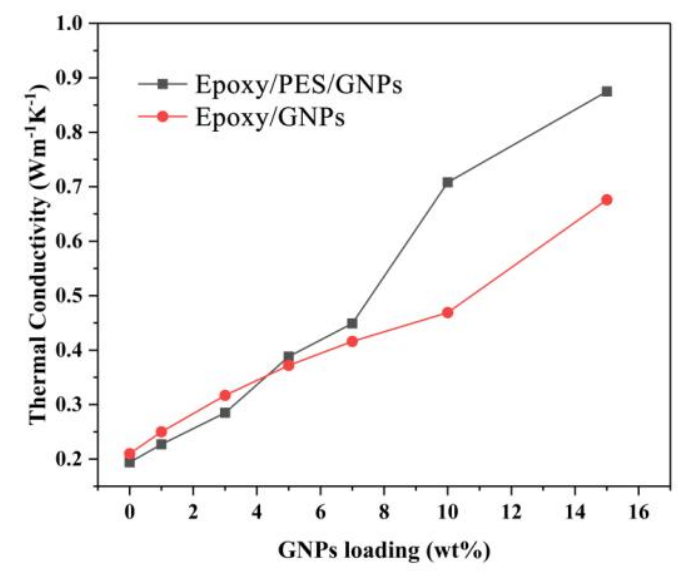

Fig. 7
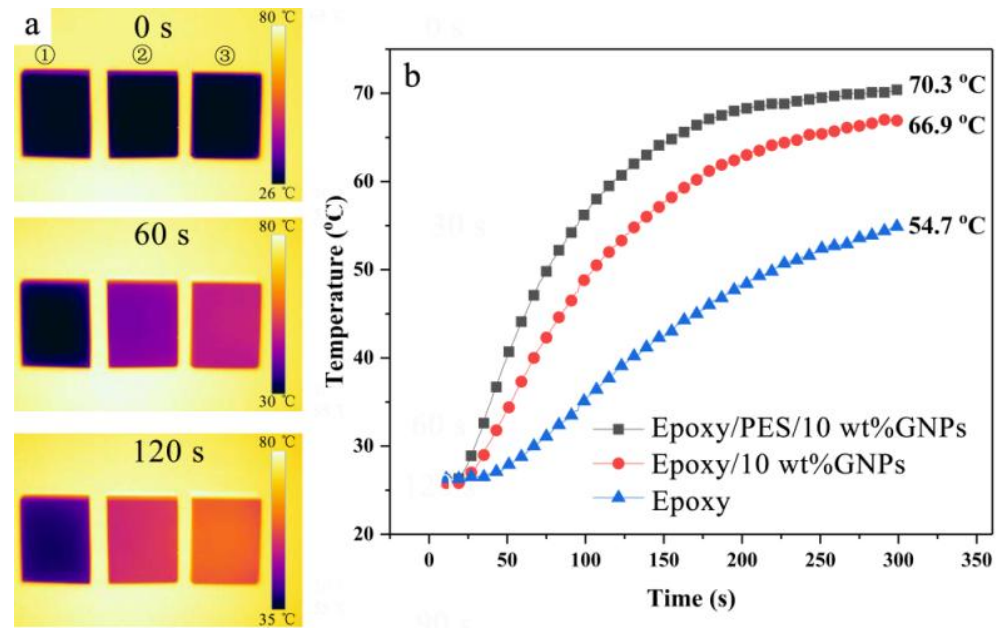

Fig. 8
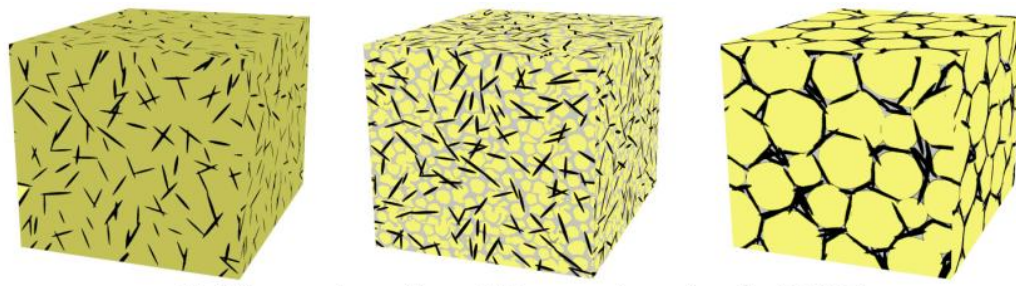

Homogeneous

blend

Epoxy

PES

Self-constructing filler network via RIPS

GNPs

Fig. 9 


\begin{tabular}{cccc}
\hline Components & $\gamma^{\mathrm{d}}\left(\mathrm{mN} \mathrm{m}^{-1}\right)$ & $\gamma^{\mathrm{p}}\left(\mathrm{mN} \mathrm{m}^{-1}\right)$ & $\gamma\left(\mathrm{mN} \mathrm{m}^{-1}\right)$ \\
\hline PES & 27.9 & 9.8 & 37.7 \\
Epoxy & 38.5 & 13.7 & 52.2 \\
GNPs & 39.5 & 6.6 & 46.1 \\
\hline
\end{tabular}

Table 1

\begin{tabular}{lcc}
\hline \multirow{2}{*}{$\begin{array}{c}c \\
\text { comple }\end{array}$} & \multicolumn{2}{c}{$\gamma_{\mathrm{A}-\mathrm{B}}\left(\mathrm{mN} \mathrm{m}^{-1}\right)$} \\
\cline { 2 - 3 } & Based on the harmonic mean & Based on the geometric mean \\
\hline PES-GNPs & 2.62 & 1.48 \\
Epoxy-GNPs & 2.50 & 1.29 \\
PES-Epoxy & 2.64 & 1.48 \\
\hline
\end{tabular}

Table 2

\begin{tabular}{lcc}
\hline Composite & $\omega_{\mathrm{a}}$ calculated from the & $\omega_{\mathrm{a}}$ calculated from the \\
& harmonic mean equation & geometric mean equation \\
\hline Epoxy/PES/GNPs & 0.05 & 0.02 \\
\hline
\end{tabular}

Table 3 


\begin{tabular}{ccc}
\hline Matrix & GNPs content $(\mathrm{wt} \%)$ & Impact strength $\left(\mathrm{kJ} \mathrm{m}^{-2}\right)$ \\
\hline Pure Epoxy & 0 & $3.66 \pm 0.53$ \\
Epoxy/PES & 0 & $3.49 \pm 0.55$ \\
Epoxy/PES & 1 & $4.77 \pm 0.73$ \\
Epoxy/PES & 3 & $4.18 \pm 0.95$ \\
Epoxy/PES & 5 & $4.65 \pm 0.48$ \\
Epoxy/PES & 7 & $4.06 \pm 0.55$ \\
Epoxy/PES & 10 & $4.48 \pm 0.42$ \\
Epoxy/PES & 15 & $3.70 \pm 0.39$ \\
\hline
\end{tabular}

Table 4 